\title{
HUBUNGAN STIKERISASI PROGRAM PERENCANAAN PERSALINAN DAN PENCEGAHAN KOMPLIKASI DENGAN PENANGANAN KOMPLIKASI
}

\author{
Nursiyam, Elvi Destariyani, Ratna Dewi \\ Politeknik Kesehatan Kementerian Kesehatan Bengkulu, Program Studi D-IV Kebidanan, \\ Jalan Indragiri Nomor 03 Padang Harapan Kota Bengkulu \\ ratna_kos@yahoo.com
}

\begin{abstract}
The direct causes of maternal mortality in Indonesia is bleeding (32\%), postpartum hemorrhage, eclampsia (13\%), unsafe abortion (11\%), infection (10\%) and obstructed labor (9\%). P4K with stickers is a breakthrough in reducing maternal mortality and newborn. The high incidence of obstetric complications in the District of Talbot District Seluma. The purpose of the study to determine the relationship stikerisasi $\mathrm{P} 4 \mathrm{~K}$ with handling complications in postpartum mothers. The study design was a descriptive, cross-sectional design. Data obtained from secondary data sheet checklist. The samples were puerperal women who experience complications. Sampling with a total sampling technique. The results showed $81.4 \%$ had $87.3 \%$ stikerisasi $\mathrm{P} 4 \mathrm{~K}$ and already getting treatment complications. The results showed no relationship between stikerisasi $\mathrm{P} 4 \mathrm{~K}$ with handling complications $(p=0,000<$ , 005 and $\mathrm{OR}=55,688$ ). Expected midwife as further improve performance by IEC on P4K.
\end{abstract}

Keywords : P4K, sticker, complication treatment.

\begin{abstract}
Abstrak : Penyebab langsung dari AKI di Indonesia adalah perdarahan (32\%), perdarahan pospartum, eklampsi (13\%), aborsi tidak aman (11\%), infeksi (10\%) dan partus lama (9\%). $\mathrm{P} 4 \mathrm{~K}$ dengan stiker merupakan terobosan dalam penurunan angka kematian ibu dan bayi baru lahir. Tingginya kejadian komplikasi kebidanan di wilayah Kecamatan Sukaraja Kabupaten Seluma. Tujuan penelitian untuk mengetahui hubungan stikerisasi P4K dengan penanganan komplikasi pada ibu nifas. Desain penelitian adalah deskriptif, rancangan cross sectional. Data diperoleh dari data sekunder dengan lembar ceklist. Sampel penelitian adalah ibu nifas yang mengalami komplikasi. Pengambilan sampel dengan teknik total sampling. Hasil penelitian menunjukkan 81,4\% sudah stikerisasi P4K dan 87,3\% sudah mendapatkan penanganan komplikasi. Hasil menunjukkan ada hubungan antara stikerisasi P4K dengan penanganan komplikasi $(p=0,000<, 005$ dan $\mathrm{OR}=55,688)$. Diharapkan bidan sebagai lebih meningkatkan kinerja dengan melakukan KIE tentang P4K.
\end{abstract}

Kata kunci : P4K, stiker, penanganan komplikasi

Angka Kematian Ibu (AKI) menjadi indikator keberhasilan pembangunan pada sektor kesehatan. Menurut World Health Organization (WHO), diperkirakan kematian maternal terjadi lebih dari 500.000 kasus per tahun di seluruh dunia, yang terjadi akibat proses reproduksi. Sebagian besar kasus kematian ibu di dunia terjadi di negara-negara berkembang, termasuk di Indonesia (Tanjung, 2004).

Angka kematian ibu di Indonesia, ternyata masih tergolong tinggi. Berdasarkan hasil Survei Dasar Kesehatan Indonesia (SDKI) tahun 2012, diketahui bahwa AKI di Indonesia sebesar 214 per 100.000 kelahiran hidup (Kemenkes RI, 2013).

Kematian ibu adalah kematian seorang ibu sewaktu hamil atau dalam waktu 42 hari sesudah berakhirnya kehamilan, tidak bergantung pada tempat atau usia kehamilan. Penyebab langsung dari kematian ibu di Indonesia adalah perdarahan (32\%) terutama perdarahan post partum, eklamsia (13\%), aborsi tidak aman (11\%), infeksi (10\%), dan 
partus lama (9\%), sedangkan penyebab lainnya adalah anemia dan seperti malaria, TBC, hepatitis atau HIV/AIDS (15\%). Penyebab tak langsung yaitu pendidikan, sosial ekonomi dan sosial budaya, 4 terlalu yaitu terlalu muda untuk melahirkan, terlalu banyak anak, terlalu dekat jarak kehamilan dan terlalu tua untuk melahirkan (Kemenkes RI, 2013).

Angka kematian ibu di Provinsi Bengkulu tahun 2011 meningkat yaitu sebesar 120 per 100.000 kelahiran hidup dari 115 per 100.000 kelahiran hidup pada tahun 2010 . Jumlah kematian ibu sebanyak 40 kasus $(0,09 \%)$ yang terdiri dari kematian ibu hamil 9 orang, kematian ibu bersalin 20 orang, dan kematian ibu nifas sebanyak 11 orang (Dinkes Propinsi Bengkulu, 2012).

Nilai AKI diberbagai lingkup wilayah yang cukup besar dan dalam mengatasi kasus komplikasi kehamilan, maka pada tahun 2007 Menteri Kesehatan mencanangkan Program Perencanaan Persalinan dan Pencegahan Komplikasi (P4K) dengan stiker yang merupakan terobosan baru dalam percepatan penurunan angka kematian ibu dan bayi baru lahir melalui kegiatan peningkatan akses dan kualitas pelayanan yang sekaligus merupakan kegiatan yang membangun potensi mayarakat, kepedulian persiapan persalinan dan tindakan dalam penyelamatan ibu dan bayi baru lahir (Rinayati, 2012).

Kegiatan P4K meliputi pencatatan ibu hamil, dana sosial ibu bersalin (dasolin)/tabungan ibu bersalin (tabulin), donor darah, transport/ambulan desa, suami/keluarga menemani ibu pada saat bersalin, inisiasi menyusui dini (IMD), kunjungan nifas dan kunjungan rumah (Dwijayanti, 2013). Melalui Program Perencanaan Persalinan dan Pencegahan Komplikasi (P4K) dengan stiker yang ditempelkan di rumah ibu hamil, maka setiap ibu hamil akan tercatat, terdata dan terpantau secara tepat. Dengan data dalam stiker, diharapkan suami, keluarga, kader, dukun, bersama bidan di desa dapat memantau secara intensif keadaan dan perkembangan kesehatan ibu hamil, sehingga proses persalinan sampai dengan nifas termasuk rujukan penanganan komplikasi dapat ber- jalan dengan aman dan selamat. Hal ini didukung dengan penelitian Rohmi (2010) diketahui terdapat hubungan yang sangat bermakna antara perencanaan tentang penolong persalinan dengan ketepatan rujukan komplikasi obstetri.

Perencanaan tentang penolong persalinan berhubungan dengan ketepatan rujukan, karena ibu dan keluarga akan lebih cepat membuat keputusan tentang kemana dan siapa penolong persalinannya jika sewaktuwaktu terjadi komplikasi pada ibu hamil dan bersalin. Hal ini didukung oleh penelitian yang dilakukan oleh Retnowati (2009) dengan hasil terdapat hubungan antara penerapan $\mathrm{P} 4 \mathrm{~K}$ dengan upaya pencegahan komplikasi kehamilan.

Upaya percepatan pelaksanaan $\mathrm{P} 4 \mathrm{~K}$ dengan stiker diharapkan target mencapai 90\%. Cakupan di Indonesia tahun 2011 tercatat $61.731(80 \%)$ desa/kelurahan telah melaksanakan P4K. Menurut profil kesehatan Propinsi Bengkulu tahun 2012 jumlah bumil 39.163 orang, bumil resti komplikasi 7833 orang yang ditangani 4402 orang (56,2\%). Dari 9 kabupaten dan kota, penanganan komplikasi teringgi pada kabupaten Kepahyang dengan jumlah bumil 3544 jumlah bumil resti 709 yang di tangani 566 $(80 \%)$ dan terendah ada pada Kabupaten Seluma dengan jumlah bumil 4062 jumlah bumil resti komplikasi 812 yang di tangani $157(19 \%)$ sedangkan jumlah ibu hamil yang telah dilakukan stikerisasi di Kabupaten Seluma adalah sebanyak 546 orang (80\%). Wilayah Kecamatan Sukaraja merupakan salah satu kecamatan di Kabupaten Seluma dengan jumlah ibu hamil komplikasi yang tinggi dibandingkan dengan puskesmas yang ada di Kabupaten Seluma yaitu dari 670 ibu hamil terdapat 134 orang (20\%) yang mengalami komplikasi (Dinkes Seluma, 2013).

Berdasarkan hasil survey pendahuluan yang dilakukan peneliti bulan September 2013 di 3 Puskesmas di wilayah Kecamatan Sukaraja yaitu puskesmas Babatan, Puskesmas Cahaya Negeri dan Puskesmas Riak Siabun terhadap 5 orang ibu melahirkan yang mempunyai riwayat resiko tinggi didapatkan 
bahwa 4 orang (80 \%) yang dilakukan stikeri-sasi pada saat hamil dan 1 orang (20\%) yang tidak dilakukan stikerisasi pada saat hamil. Dari 4 orang yang dilakukan stikerisasi pada saat kehamilan menyatakan bahwa penanganan komplikasinya lebih cepat dikarenakan perencanaan persalinan seperti penolong persalinan, suami dan keluarga sebagai pendamping persalinan, transportasi, calon pendonor darah sudah siap pada saat persalinan, sedangkan 1 orang yang tidak dilakukan stikerisasi menyatakan penanganan komplikasinya lambat dikarenakan proses perencanaan persalinan tidak dilakukan secara baik dimana penolong persalinan belum ditentukan, suami dan keluarga sebagai pendamping persalinan, transporttasi, calon pendonor darah tidak siap pada saat persalinan. Hal ini menunjukkan bahwa stikerisasi program $\mathrm{P} 4 \mathrm{~K}$ mempengaruhi proses penanganan komplikasi kehamilan.

Tujuan penelitian ini adalah untuk mengetahui hubungan stikerisasi program perencanaan persalinan dan pencegahan komplikasi dengan penanganan komplikasi pada ibu nifas di wilayah Kecamatan Sukaraja Kabupaten Seluma tahun 2012

\section{BAHAN DAN CARA KERJA}

Desain penelitian yang digunakan pada penelitian ini adalah analisis deskriptif dengan rancangan potong silang, yaitu suatu penelitian dimana variabel-variabel yang termasuk faktor risiko dan variabel-variabel yang termasuk efek diobservasi sekaligus dinilai pada waktu yang sama.

Pengambilan sampel dalam penelitian ini dengan menggunakan tekhnik "total sampling" yaitu seluruh populasi dijadikan sebagai sampel. Variabel penelitian ini meliputi variabel independen (variabel bebas) stikerisasi P4K dan variabel dependen (variabel terikat) penanganan komplikasi. Populasi dalam penelitian ini adalah ibu yang memiliki bayi 0-1 tahun yang mengalami komplikasi di wilayah Kecamatan Sukaraja tahun 2012 yang terdiri dari 3 Puskesmas yaitu Puskesmas Babatan, Puskesmas Cahaya Negeri dan Puskesmas Riak Siabun yang berjumlah 127 orang.

\section{HASIL PENELITIAN}

Analisis Univariat

Tabel 1. Distribusi frekuensi karakteristik ibu yang memiliki bayi 0-1 tahun dan jenis komplikasi

\begin{tabular}{lcc}
\hline \multicolumn{1}{c}{ Variabel } & \multicolumn{2}{c}{ Frekuensi Presentase } \\
& $(\mathbf{n = 1 0 2})$ & $(\mathbf{1 0 0 \% )}$ \\
\hline Umur & & \\
$<$ 20 Tahun dan > 35 tahun & $\mathbf{2 9}$ & 28,4 \\
20-35 Tahun & $\mathbf{7 3}$ & 71,6 \\
Paritas & & \\
Primipara & $\mathbf{2 7}$ & 26,5 \\
Multipara & $\mathbf{7 5}$ & 73,5 \\
Pendidikan & & \\
Rendah & $\mathbf{6 5}$ & 63,7 \\
Tinggi & $\mathbf{3 7}$ & 36,3 \\
Sikerisasi P4K & & \\
Tidak Stikerisasi & $\mathbf{1 9}$ & 18,6 \\
Stikerisasi & $\mathbf{8 3}$ & 81,4 \\
Penanganan Komplikasi & & \\
Tidak Ditangani & $\mathbf{1 3}$ & 12,7 \\
Ditangani & 89 & 87,3 \\
\hline
\end{tabular}

Analisis ini dilakukan untuk mendapatkan gambaran tentang stikerisasi Program Perencanaan Persalinan dan Pencegahan Komplikasi (P4K) dan penanganan komplikasi pada ibu yang memiliki bayi 0-1 tahun di wilayah Kecamatan Sukaraja Kabupaten Seluma tahun 2012.

Hasil analisis pada tabel 1 menunjukkan bahwa dari 102 responden dengan komplikasi yang memiliki bayi 0-1 tahun terdapat sebagian besar $(71,6 \%)$ yang berumur 20-35 tahun, sebagian besar $(73,5 \%)$ dengan paritas multipara, sebagian besar $(63,7 \%)$ berpendidikan rendah. Hampir seluruh responden yang memiliki bayi $0-1$ tahun $(81,4, \%)$ telah dilakukan stikerisasi $\mathrm{P} 4 \mathrm{~K}$, dan hampir seluruh responden $(87,3 \%)$ mendapatkan penanganan komplikasi.

\section{Analisis Bivariat}

Berdasarkan tabel 2, terlihat bahwa dari 19 responden yang tidak mendapatkan stikerisasi P4K sebagian besar $(57,9 \%)$ yang komplikasinya tidak tertangani, dan dari 83 responden yang mendapatkan stikerisasi P4K hampir seluruh $(87,6 \%)$ yang komplikasinya ditangani. Hasil uji statistik didapat $p=0,000 \leq \alpha=0,05$, berarti terdapat hubungan yang bermakna antara stikerisasi program 
perencanaan persalinan dan pencegahan komplikasi dengan penanganan komplikasi pada ibu yang memiliki bayi 0-1 tahun di wilayah Kecamatan Sukaraja Kabupaten Seluma tahun 2012.

Berdasarkan tabel 2, terlihat bahwa dari 29 responden yang berumur $<20$ tahun/> 35 tahun hampir seluruhnya $(82,8 \%)$ yang komplikasinya tertangani, dan dari 73 responden yang berumur 20-35 tahun hampir seluruhnya $(95,9 \%)$ yang komplikasinya ditangani. Hasil uji statistik didapat $p=0,040<$ $\alpha=0,05$. Ini menunjukkan secara statistik terdapat hubungan yang bermakna antara umur dengan penanganan komplikasi pada ibu yang memiliki bayi 0-1 tahun di wilayah Kecamatan Sukaraja Kabupaten Seluma tahun 2012.

Tabel 2. Hubungan stikerisasi P4K dengan penanganan komplikasi pada ibu yang memiliki bayi 0-1 tahun

\begin{tabular}{|c|c|c|c|c|c|c|c|}
\hline \multirow{3}{*}{ Variabel } & \multicolumn{4}{|c|}{$\begin{array}{c}\text { Penanganan } \\
\text { Komplikasi }\end{array}$} & \multicolumn{2}{|c|}{ Total } & \multirow{3}{*}{ Nilaip } \\
\hline & \multicolumn{2}{|c|}{$\begin{array}{c}\text { Tidak Di- } \\
\text { tangani }\end{array}$} & \multicolumn{2}{|c|}{ Di-tangani } & \multirow[t]{2}{*}{$\mathrm{n}$} & \multirow[t]{2}{*}{$\%$} & \\
\hline & $\mathrm{n}$ & $\%$ & $\mathrm{n}$ & $\%$ & & & \\
\hline \multicolumn{8}{|l|}{ Stikerisasi P4K } \\
\hline Tidak Stikerisasi & 11 & $\mathbf{5 7 , 9}$ & 8 & 42,1 & 19 & 100 & 0,000 \\
\hline Stikerisasi & 2 & 2,4 & 81 & 87,6 & 83 & 100 & \\
\hline \multicolumn{8}{|l|}{ Umur } \\
\hline $\begin{array}{l}<20 \text { tahun } />35 \\
\text { tahun }\end{array}$ & 5 & 17,2 & 24 & 82,8 & 29 & 100 & 0,040 \\
\hline 20-35 Tahun & 3 & 4,1 & 70 & 95,9 & 73 & 100 & \\
\hline \multicolumn{8}{|l|}{ Paritas } \\
\hline Primipara & 1 & 3,7 & 26 & 96,3 & 27 & 100 & 0,678 \\
\hline Multipara & 7 & 9,3 & 68 & 90,7 & 75 & 100 & \\
\hline \multicolumn{8}{|l|}{ Pendidikan } \\
\hline Rendah & 7 & 10,8 & 58 & 89,2 & 65 & 100 & 0,253 \\
\hline Tinggi & 1 & 2,7 & 36 & 97,3 & 37 & 100 & \\
\hline
\end{tabular}

Berdasarkan tabel 2, terlihat bahwa dari 27 responden dengan paritas primipara hampir seluruhnya $(96,3 \%)$ yang komplikasinya tertangani, dan dari 75 responden dengan paritas multipara hampir seluruhnya (90,7\%) yang komplikasinya ditangani. Hasil uji statistik didapat $p=0,678>\alpha=0,05$. Ini menunjukkan secara statistik tidak terdapat hubungan yang bermakna antara paritas dengan penanganan komplikasi pada ibu yang memiliki bayi 0-1 tahun di wilayah Kecamatan Sukaraja Kabupaten Seluma tahun 2012.

Berdasarkan tabel 2, terlihat bahwa dari 65 responden yang berpendidikan rendah hampir seluruhnya $(89,2 \%)$ yang komplikasinya tertangani, dan dari 37 responden yang berpendidikan tinggi hampir seluruhnya $(97,3 \%)$ yang komplikasinya ditangani. Hasil uji statistik didapat $p=0,253>\alpha=0,05$. Ini menunjukkan secara statistik tidak terdapat hubungan yang bermakna antara pendidikan dengan penanganan komplikasi pada ibu yang memiliki bayi 0-1 tahun di wilayah Kecamatan Sukaraja Kabupaten Seluma tahun 2012.

\section{PEMBAHASAN}

\section{Pelaksanaan stikerisasi program P4K}

Berdasarkan hasil penelitian diperoleh $81,4 \%$ yang stikerisasi, hasil tersebut hampir mencapai target nasional yaitu 90\%. Hasil penelitian ini menunjukkan bahwa pemasangan stiker pada ibu hamil sudah hampir mencapai target. Hal ini disebabkan hampir seluruh ibu hamil memeriksakan kehamilannya pada bidan. Bidan sebagai penggerak program $\mathrm{P} 4 \mathrm{~K}$ sudah bekerja secara maksimal dalam mensosialisasikan program $\mathrm{P} 4 \mathrm{~K}$, baik pada saat pemeriksaan kehamilan, posyandu, pertemuan dasawisma, PKK, arisan dan semua kegiatan yang melibatkan ibu-ibu.

Berdasarkan hasil penelitian masih ditemukan sebagian kecil responden yang tidak mendapatkan stikerisasi, dimana masih ada responden yang memang tidak mendapat stiker dan mendapat stiker tetapi tidak ditempel pada tempat yang tepat yaitu di pintu depan rumah. Hal ini disebabkan sebagian besar dari responden masih rendah tingkat pendidikannya. Makin tinggi tingkat pendidikan seseorang, makin mudah menerima informasi sehingga makin banyak pula pengetahuan yang dimiliki, sebaliknya pendidikan yang kurang akan menghambat perkembangan sikap seseorang terhadap perubahan hidup sehat (Notoatmodjo, 207). 
Makin tinggi atau rendahnya pendidikan responden sangat erat hubungannya dengan tingkat kesadaran ibu dalam menempel stiker P4K. Hasil penelitian menunjukkan masih perlunya tenaga kesehatan (bidan) untuk melakukan KIE tentang program $\mathrm{P} 4 \mathrm{~K}$.

\section{Penanganan komplikasi}

Hasil penelitian ini menunjukkan bahwa masih terdapat ibu yang mengalami komplikasi yang tidak tertangani. Komplikasi yang terbanyak yaitu perdarahan dengan jenis perdarahan karena atonia uteri, retensio plasenta, plasenta previa, robekan jalan lahir, solusio plasenta, sisa plasenta, $\mathrm{AB}$ iminens dan karena sebab lain. Tingginya angka kejadian perdarahan disebabkan masih ada usia ibu hamil $<20$ tahun atau $>35$ tahun serta masih ada ibu dengan paritas grandemultipara. Usia reproduksi yang aman bagi wanita untuk hamil dan melahirkan adalah usia 20-35 tahun, usia kurang dari 20 tahun atau lebih 35 tahun meningkatkan resiko terjadinya komplikasi. Hal tersebut berhubungan dengan fungsi anatomi dan fisiologis alat reproduksi (Detiana, 2010)

Berdasarkan tabel 4.1, menunjukkan sebagian kecil responden yang komplikasinya tidak tertangani. Hal ini disebabkan karena beberapa alasan, antara lain jarak rumah responden ke fasilitas kesehatan yang jauh, sejak dari awal responden tidak memeriksakan kehamilannya dengan alasan malu karena usia yang sudah tua, jumlah anak yang sudah banyak, atau jarak anak terlalu dekat dan kehamilan di luar nikah, sehingga mengakibatkan ibu tidak mendapatkan informasi tentang kesehatan termasuk informasi tentang program P4K. Pemeriksaan kehamilan hanya dilakukan oleh dukun beranak sehingga pada saat ibu mengalami komplikasi kehamilan, persalinan maupun nifas, penanganan komplikasi hanya dilakukan oleh dukun beranak.

Menurut Kamaliah (2012), penanganan komplikasi kebidanan adalah pelayanan kepada ibu dengan komplikasi kebidanan untuk mendapat penanganan definitif sesuai standar oleh tenaga kesehatan kompeten pada tingkat pelayanan dasar dan rujukan. Diper- kirakan sekitar 15-20 \% ibu hamil akan mengalami komplikasi kebidanan. Komplikasi dalam kehamilan dan persalinan tidak selalu dapat diduga sebelumnya, oleh karenanya semua persalinan harus ditolong oleh tenaga kesehatan agar komplikasi kebidanan dapat segera dideteksi dan ditangani.

\section{Hubungan stikerisasi P4K, karakteristik responden dengan penanganan komplikasi}

Hasil uji statistik menunjukkan ada hubungan yang bermakna antara stikerisasi program perencanaan persalinan dan pencegahan komplikasi dengan penanganan komplikasi pada ibu yang memiliki bayi $0-1$ tahun di wilayah Kecamatan Sukaraja Kabupaten Seluma tahun 2012. Hasil penelitian ini sependapat dengan penelitian Rohmi (2010) tentang hubungan antara perencanaan tentang penolong persalinan dengan ketepatan rujukan obstetri didapat hasil bahwa terdapat hubungan yang sangat bermakna antara perencanaan tentang penolong persalinan dengan ketepatan rujukan obstetri. Perencanaan tentang penolong persalinan berhubungan dengan ketepatan rujukan, karena ibu dan keluarga akan lebih cepat membuat keputusan tentang kemana dan siapa penolong persalinannya jika sewaktu-waktu terjadi komplikasi pada ibu hamil dan bersalin. Penolong persalinan tersebut diharapkan adalah tenaga kesehatan sehingga pertolongan pertama yang adekuat segera bisa diberikan termasuk rujukan yang aman dan tepat waktu dan terhindar dari rujukan yang estafet (berantai).

Hasil penelitian ini sesuai dengan penelitian yang dilakukan oleh Retnowati (2010), yang menunjukkan bahwa ada hubungan yang signifikan antara penerapan program perencanaan persalinan dan pencegahan komplikasi ( $\mathrm{P} 4 \mathrm{~K})$ dengan upaya pencegahan komplikasi kehamilan. Hasil penelitian membuktikan belum sepenuhnya upaya pencegahan komplikasi kehamilan dilakukan dengan baik. Faktor tempat pelayanan kesehatan dan petugas kesehatan serta dari individu ibu hamil mempengaruhi upaya pencegahan komplikasi kehamilan tidak dilaksanakan dengan baik. Keaktifan ibu hamil dan tenaga kesehatan, diharapkan mam- 
pu meningkatkan upaya pencegahan komplikasi kehamilan dengan baik. Keterbatasan fasilitas alat pelayanan kesehatan memang perlu diperhatikan oleh semua pihak, sehingga dapat memberikan asuhan pada ibu hamil sesuai standar.

Pemasangan stiker P4K bukanlah sekedar menempelkan stiker pada setiap rumah ibu hamil, tapi harus dilakukan konseling kepada ibu hamil, suami dan keluarga untuk mendapatkan kesepakatan dan kesiapan dalam merencanakan persalinan. Melalui stiker, pendataan dan pemantauan ibu hamil dapat dilakukan secara intensif oleh bidan bersama dengan suami, keluarga, kader, masyarakat, forum peduli KIA, serta pendeteksian dini kejadian komplikasi sehingga ibu hamil dapat menjalani kehamilan dan persalinan dengan aman dan selamat, serta bayi yang dilahirkan sehat (Runjati, 2010).

Berdasarkan hasil penelitian terdapat 8 responden $(42,1 \%)$ yang tidak mendapat stiker P4K tetapi komplikasinya tertangani, hal ini tidak terlepas dari peran serta kader posyandu sebagai perpanjangan tangan dari petugas kesehatan. Saat posyandu kader mensosialisasikan program P4K. Pada saat tertentu kader menemukan komplikasi kebidanan, hal ini ia sampaikan kepada bidan sehingga bidan dapat segera melakukan penanganan komplikasi agar komplikasi yang terjadi tidak berkelanjutan. Selain kader, bidan juga bermitra dengan dukun bayi. Di sebagian tempat, dukun bayi adalah orang yang paling dipercaya oleh responden dan keluarga termasuk dimana peneliti melakukan penelitian, selain sebagai penolong persalinan, dukun juga dapat melakukan deteksi dini terhadap komplikasi yang dialami ibu, selanjutnya dukun melakukan rujukan kepada agar bidan menindaklanjuti rujukan dari dukun sehingga komplikasi yang dialami responden tidak berkelanjutan dan segera mendapat penanganan.

Hasil penelitian juga menemukan sebagian kecil responden yang telah stikerisasi P4K tetapi komplikasinya tidak tertangani, hal ini disebabkan sikap sebagian responden yang menganggap komplikasi yang dihadapinya adalah hal yang normal atau biasa, dan akan sembuh sendiri hanya dengan menggunakan obat-obatan sederhana (tradisional) atau ibu merasa penanganan komplikasi yang didapatkan dari dukun sudah cukup, sehingga tidak perlu menghubungi petugas kesehatan. Namun jika dengan pengobatan sederhana (tradisional) atau dengan bantuan dukun komplikasi ibu masih berlanjut, maka responden merasa perlu untuk menghubungi tenaga kesehatan.

Hasil penelitian ini menunjukkan bahwa rendahnya pendidikan responden akan berpengaruh terhadap perilaku, dimana orang yang mempunyai pendidikan rendah akan sulit untuk menerima informasi. Hasil penelitian ini sesuai dengan pendapat Notoatmodjo (2007), bahwa makin tinggi tingkat pendidikan seseorang, maka semakin mudah seseorang itu untuk menerima informasi begitu juga sebaliknya pendidikan yang kurang akan menghambat perkembangan sikap seseorang dan perubahan perilaku seseorang.

Tidak tertanganinya komplikasi juga disebabkan masih adanya ibu tidak melakukan pemeriksaan kehamilan secara rutin yaitu 1 kali trimester 1,1 kali trimester 2 dan 2 kali pada trimester 3 (minimal 4 kali) dan bidan tidak melakukan kunjungan rumah terhadap ibu yang tidak ANC secara rutin, selain itu pada saat nifas bidan tidak melakukan kunjungan ulang yang seharusnya sesuai dengan standar kunjungan nifas yaitu kunjungan ke-1 (6-8 jam setelah persalinan), kunjungan ke-2 (6 hari setelah persalinan), kunjungan ke-3 (2 minggu setelah persalinan) dan kunjungan ke-4 (6 minggu setelah persalinan), yang pada akhirnya ketika responden mengalami komplikasi tidak mendapatkan penanganan dari tenaga kesehatan. Hal ini tidak akan terjadi jika bidan atau tenaga kesehatan bekerja sesuai peran dan fungsinya.

Selain faktor stikerisasi $\mathrm{P} 4 \mathrm{~K}$, juga terdapat faktor lain yang dapat mempengaruhi tertangani komplikasi seperti lain jarak rumah responden ke fasilitas kesehatan yang jauh, sejak dari awal responden tidak memeriksakan kehamilannya dengan alasan malu karena usia yang sudah tua, jumlah anak 
yang sudah banyak (grandemultipara), atau jarak anak terlalu dekat dan kehamilan di luar nikah.

Berdasarkan dari nilai OR, diperoleh bahwa nilai OR terbesar adalah untuk variabel stikerisasi P4K yaitu sebesar 55,688, hasil penelitian ini menunjukkan bahwa penanganan komplikasi juga dipengaruhi oleh umur ibu $(\mathrm{OR}=4,861)$, tetapi bila dilihat nilai OR stikerisasi lebih besar pengaruhnya dimana responden yang tidak stikerisasi P4K mempunyai peluang 12,883 kali komplikasinya tidak tertangani dibandingkan dengan responden yang stikerisasi $\mathrm{P} 4 \mathrm{~K}$. Hal ini juga berarti bahwa faktor stikerisasi $\mathrm{P} 4 \mathrm{~K}$ lebih dominan dalam mempengaruhi penanganan komplikasi dibandingkan dengan faktor umur, paritas dan pendidikan.

\section{DAFTAR RUJUKAN}

Depkes RI, 2009, Program Perencanaan Persalinan dan Pencegahan Komplikasi (P4K) dengan Stiker, Jakarta : Depkes RI.

Detiana, 2010, Hamil Aman dan Nyaman di Atas Usia 30 Tahun. Yogyakarta: Media Pressindo.

Dinkes Provinsi Bengkulu, 2009, Peran Program Perencanaan Persalinan \& Pencegahan Komplikasi (P4K) Dalam Pelaksanaan Pembangunan Pelaksanaan Kesehatan Dan Kesehatan KB. Bengkulu : Dinkes Provinsi Bengkulu.

, 2012, Profil Kesehatan Provinsi
$\begin{aligned} & \text { Bengkulu. Bengkulu }: \text { Dinkes Provinsi } \\ & \text { Bengkulu. }\end{aligned}$
Dinkes Seluma, 2012, Profil Kesehatan Kabupaten Seluma. Seluma : Dinkes Seluma.

Dwijayanti, 2013. Analisis Implementasi Program Perencanaan Dan Pencegahan Komplikasi (P4K) Oleh Bidan Desa Di Kabupaten Demak, Semarang : Jurnal Kesehatan Masyarakat 2013 Volume 2, Nomor 1, Tahun 2013. Fakultas Kesehatan Masyarakat Universitas Diponegoro.

Kamaliah, 2012, Beberapa Faktor Yang Berhubungan Dengan Terjadinya Komplikasi Kehamilan Dan Persalinan Di Rumah Sakit Haji Medan Tahun 2002-2003, Medan : Universitas Sumatera Utara.

\section{KESIMPULAN}

Hasil penelitian menunjukan bahwa sebagian besar responden berumur 20-35 tahun, paritas multipara. berpendidikan rendah, dan hampir seluruh responden sudah dilakukan stikerisasi P4K serta sudah mendapatkan penanganan komplikasi. Ada hubungan antara stikerisasi $\mathrm{P} 4 \mathrm{~K}$ dengan penanganan komplikasi $(p=0,000)$.

Diharapkan agar pihak puskesmas khususnya bidan sebagai penggerak utama dalam program $\mathrm{P} 4 \mathrm{~K}$ dapat lebih meningkatkan kinerja dengan cara melakukan Komunikasi, Informasi dan Edukasi (KIE), serta melakukan kunjungan rumah pada setiap ibu hamil atau ibu nifas yang tidak melakukan kunjungan sesuai standar sebagai upaya deteksi dini komplikasi.

Kemenkes RI, 2013, Profil Kesehatan Indonesia Tahun 2013. Jakarta: Kemenkes RI

2013, Survei Dasar Kesehatan Indonesia Tahun 2012. Jakarta: Kemenkes RI

Notoatmodjo, S, 2007. Pendidikan Kesehatan da Ilmu Perilaku. PT. Andi Offset. Yogyakarta.

Retnowati, 2009. Hubungan Penerapan P4k Oleh Ibu Hamil Dengan Upaya Pencegahan Komplikasi Kehamilan Di Puskesmas Sidorejo Kidul Salatiga, Boyolali . Jurnal Kebidanan Akademi Kebidanan Estu Utomo Boyolali Volume 1 No. 2 Desember 2009. Akademi Kebidanan Estu Utomo Boyolali.

Rinayati, 2012, Studi Deskriptif Kinerja Bidan Desa Dalam Melaksanakan Program Perencanaan Persalinan Dan Pencegahan Komplikasi (P4K) Di Kabupaten Batang Tahun 2012, Semarang : STIKES Widya Husada.

Rohmi, Handayani, 2010. The Factor Analysis Of Implementation Of Birth Planning And Complication Prevention Program (BPCPP) That Related With The Precise Obstetric Referral At Banyumas District. Jurnal Fakultas Kedokteran Universitas Padjajaran . Bandung : Universitas Padjadjaran. 
